\title{
Investigating Teachers' and Students' Beliefs and Assumptions about CALL Programme at Caledonian College of Engineering
}

\author{
Holi Ibrahim Holi Ali \\ (Caledonian College of Engineering, Oman) \\ doi:10.7575/aiac.alls.v.3n.1p.94
}

\begin{abstract}
This study is set out investigate students' and teachers' perception and assumptions about newly implemented CALL Programme at the School of Foundation Studies, Caledonian College of Engineering, Oman. Two versions of questionnaire were administered to 24 teachers and 90 students to collect their beliefs and assumption about CALL programame. The results shows that the great majority of the students report that CALL is very interesting, motivating and useful to them and they learn a lot form it .However, the number of CALL hours should be increased, lab should be equipped and arranged in user friendly way, assessment should be integrated into CALL, and smart boards, black boards should be incorporated into the programme
\end{abstract}

\section{Introduction}

In current years, the computer has established itself as a significant feature of present life. One of the fields that has played a vital role is language teaching and learning. So high technology, especially the use of computer, has won a secure place among resources available to the modern language teacher. The role of computers in language teaching has changed significantly over the last decades. Recent technological and pedagogical developments provide us with more opportunities to fully integrate computer technology in language learning process language centers throughout the world, knowing that they cannot do without computers for learning purposes. So, the use of computers has positive impact on teaching and learning process. Jones (2001) points out that the chief reason for the use of computers in classroom tends to be regarded as promoting independent learning, and this autonomy is a highly valued goal in the age of communicative approach. In this respect, Levy (1997) says that the promised benefits of learner-centered and autonomy are frequently referred to in the research on Computer Assisted Language Learning (CALL). So, CALL is not a method, but it 
is a tool that helps teachers to individualize learning process. CALL can be used as a learning tool to reinforce what has been learned in the classroom.

\section{What is CALL?}

According to Beatty (2003, p. 12), CALL is "any process in which a learner uses computer, and, as a result, improves his or her language." CALL originates from CAI (Computer Accelerated Instruction). And it is also known by several other terms such as Technology Enhanced Language Learning (TELL), Computer -Assisted Language Instruction (CALI) and Computer -Aided Language Learning. It is a student-centered and accelerated learning material, which promotes self-paced accelerated learning.

Warschauer (1996) classifies CALL into three main phases

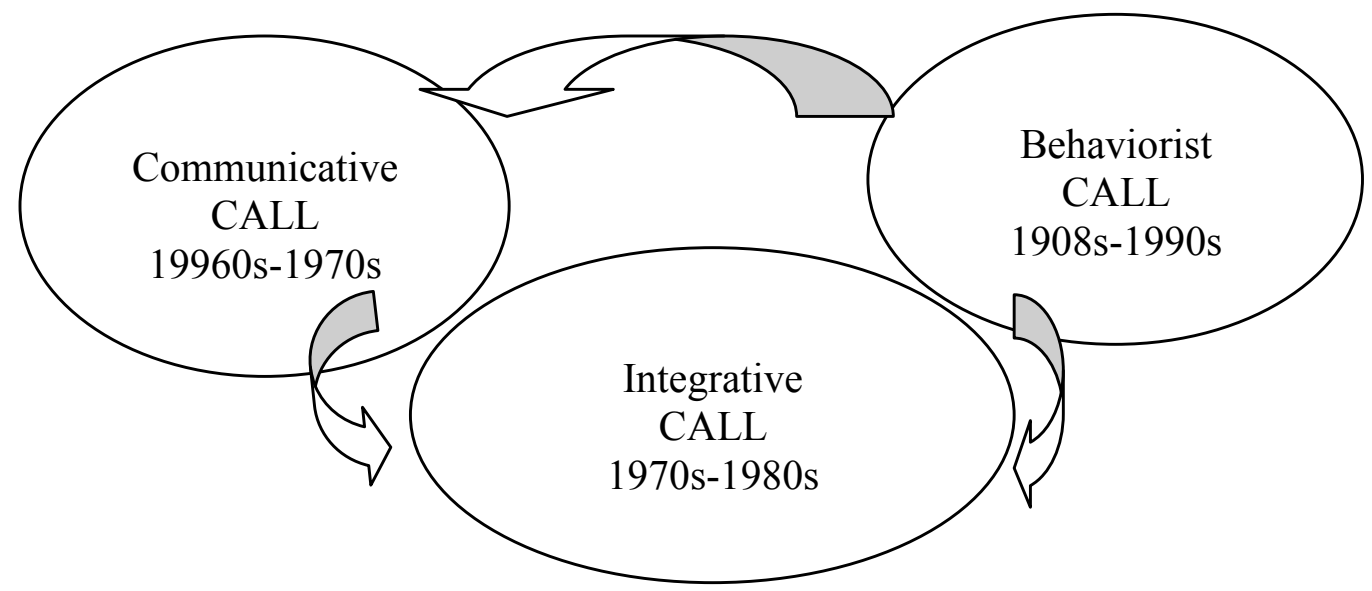

Figure 1: Historical background of CALL

Computer assisted language learning was firstly used in language learning and teaching and known as the behaviorist CALL phase. Lee (2000) points out the main feature of this stage was mechanical drilling which was based on stimulus-response theory. The computer was viewed as a tutor. The main focus in this stage was teaching grammar explicitly and translation tests.

The second phase of CALL was communicative CALL which appeared as a reaction to the behaviorist CALL. At this stage, the computer was also used as a tutor and it was based on the communicative approach which views language learning as using a language in order to learn a language rather than learning a language in order to use it. According to this approach, grammar should be taught implicitly (Al Saidi, 2007, Saeed, 2006, Lee, 2000; McGreal, 1988). 
The third CALL stage was integrative CALL which was based on a socio-cognitive view theory which emphasizes an original language use in a meaningful and authentic context. In this stage the computer was used as a teaching tool rather than as a tutor. Integrative CALL aims at integrating all skills rather than segregating them. (Lee, 2000 in Bulut, 2005, pp. 6-7).

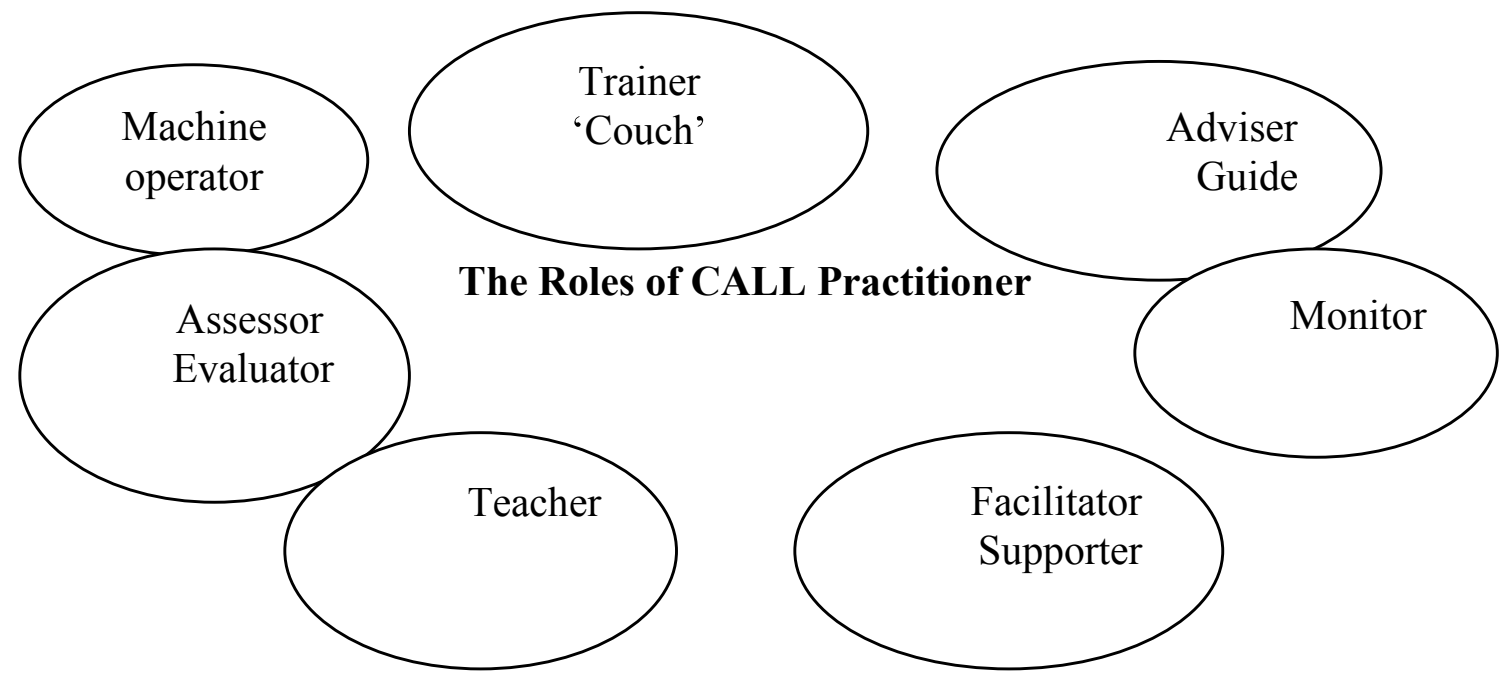

Figure 2: The roles of CALL practitioner

As far as the CALL practitioner is concerned, the effectiveness of CALL depends greatly on teachers. It undoubtedly requires teachers to train their learners in utilizing and making use of CALL effectively. More learners' training and supervision should be carried out by the teachers in CALL classes.

Levy (1997, p. 210, cited in Janes, 2001) states that CALL entails degrees of teacher intervention. A well-designed, interesting, interactive program may release a learner from teacher's supervision at an early stage, but the practitioner has to be available due to the following reasons:

- Any CALL activity at any level of proficiency, for a variety of cultural or psychological reasons, are more useful for some learners who are more teacher-dependent than others.

- CALL activity requires a teacher to be constantly on hand as a guide and adviser to provide training and help when needed.

- The entire success of CALL depends on students' careful preparation by the teacher so that they have the requisite learning strategies to use computer tools confidently and appropriately. 
CALL is a dynamic field that changes rapidly because the technology that helps to define it changes rapidly. Therefore, the role of the teacher has been radically changed instead of handing down knowledge to students and being the centres of students' attentions, teachers have become guidance as they help students to complete the assigned tasks.

At the same time, teachers have also become the monitors, facilitators, adviser, 'coach', assessor, evaluator and the teacher.

\section{Implications of CALL in language teaching and learning}

\section{Experiential learning}

The internet provides students a huge amount of human experience. Students have the chance to learn things by doing hands-on activities. They gain the ability of creating knowledge, not just receiving it. Because the information is presented in many ways, users may choose the information they want to explore (Lee, 2000 in Bulut, 2005).

\section{Motivation}

CALL fosters motivation, individualizes and personalizes learning process, promotes independent learning and engages the learner more fully.

\section{Authenticity}

CALL exposes the learner to authentic materials and real life activities.

\section{Critical thinking}

Using technology in classroom improves self-concept and provides more student -centred learning.

\section{Practicality}

CALL guarantees learning efficiency \& effectiveness. Learners are to pick up language knowledge faster with less effort and time. CALL improves keyboarding skills, develops word processing skills faster and supports writing skills.

\section{Access}

Learners can get materials with visual support or experience interactions that would otherwise be difficult or impossible to get or do. 


\section{Enhancing students' achievements}

Computer-assisted language learning may be helpful for students to strengthen their linguistic skills by positively affecting their learning styles and attitudes by making them build autonomous learning strategies.

\section{Maximizing interaction}

Lee (2000, p.2) says 'random access to Web page breaks the linear flow of instruction'. EFL students can chat with people they have never met by sending and receiving e-mails and joining chat rooms (Warschauer, 2008, Al Saidi, 2007, Beatty, 2003, Lee 2000 \& Levy, 1997).

Useful factors for normalization of CALL in the future (Georgiou, 2006)

Appropriate hardware

It is a necessary factor. Lack of basic equipment such as computers and printers can constrain development.

\section{Appropriate software}

Participants mentioned that there was lack of classroom software which agreed with current pedagogy. Most existing software is directed towards self-access and not for classroom use, thus placing obstacles for progress towards normalization.

\section{Easy access to technology}

Many participants mentioned hi-tech labs which were kept under lock-and-key as the school afraid that the school's precious possession which might be damaged by students or teachers. A key to normalization requires the teachers to have access to the technology whenever they need it and, preferably, at all times.

\section{'Top-down' policy to use computers}

Successful stories were pointed out where the decision to use computers in teaching came from the management and was strictly adhered to. Even though it is not a democratic procedure, it was found to work as long as the administration offered plenty of support to the teachers. 


\section{'Top-down' policy to use computers}

Successful stories were pointed out where the decision to use computers in teaching came from the management and was strictly adhered to. Even though it is not a democratic procedure, it was found to work as long as the administration offered plenty of support to the teachers.

\section{An integration of the technology into the syllabus}

It is important for technology to be integrated into the syllabus and not to be an extra add-on which is used whenever 'there is time'. A process which schedules technology into regular syllabus activities helps teachers and students view and use technology as an integral part of the lesson.

Teacher training as regards technological literacy

Teachers should be trained so that they are confident users of technology.

Teacher training as regards CALL implementation/pedagogy

Teachers should be trained how to implement CALL in the classroom without sacrificing language learning pedagogy.

\section{Provision of plentiful support to teachers}

Technical and pedagogical support is essential in order to save teachers' time spent on maintaining the equipment and help build teachers' confidence in their efforts to use new technological applications.

\section{Familiarization of technical support with EFL methodology}

A positive factor would be for technical staff to be initiated into FL methodology so as to improve co-operation between teaching and technical staff.

\section{Personalization of technology}

Learners and teachers should have free access to technology and should have a sense of ownership towards the technology, feel comfortable, and at ease with the tool. It was argued that perhaps for this to be achieved teachers and students should have their own computers. 
Involvement of teaching staff in decisions about technology

This is important in that it involves the teachers in the process of CALL implementation and promotes the feeling of ownership, which teachers should have about technology.

\section{Technological developments}

It was often felt that normalization could not yet be achieved because technology itself does not yet offer the tools we require. It cannot, for example, offer natural interaction/ conversation sessions.

These factors are significant in that they have been distilled from the experiences of colleagues from around the world who have been experimenting with CALL for many years. They can be seen as stepping stones to reach CALL normalization and can help to map out the path we should follow (Georgiou, S. L, 2006, pp. 382-384).

\section{Objectives of the study}

- To provide CALL coordinators and administrators with teachers' and students' beliefs , assumptions, suggestions and profound insights about the newly implemented CALL in order to improve CALL lessons or activities. The result is expected to assist in the implementation and growth of successful CALL programmes

- To know whether the time allocated for CALL lessons is enough for achieving the target objectives, and whether the way the CALL lesson are executed is satisfactory to students or not

- To examine whether the use of CALL in classroom is interesting and can motivate students to learn a language independently or not.

- To make teachers and students more aware of the importance and effectiveness of CALL in teaching and learning process in general and in launching the new foundation programme in particular.

\section{Questions of the study}

1- What are the teachers' and students' beliefs \& attitudes towards CALL?

2- Are students interested in seeking the benefits of CALL??

3- How can we improve the CALL program within the college and School of Foundation Studies in particular?

4- To what extent CALL is used in the English Language Department? 


\section{Significance and implication of the study (present and future)}

- It is considered to be a leading study of its kind and scope for investigating both teachers' and students' perceptions regarding CALL in Caledonian College of Engineering, Oman.

- The study derives its magnitude from the role of CALL as a significant eLearning tool in promoting learning autonomy. With increasing opportunities in integrated technology in classrooms, there is an increasing interest to investigate students' and teachers' attitudes and beliefs about the use of technology and its benefits for students and language learning in general.

- The study might ultimately help those who are trying to use technology to foster independent learning.

- Most importantly, the study strives to lay the basis for investigating the use of CALL and technology in general in teaching a language and reinforcing learning within the college and School of Foundation in particular.

\section{Limitations of the study}

- The study doesn't include the use of CALL in other departments such as EPD.

- The study bounds to 24 teachers \& 90 students, from the School of Foundation Studies only, which are not a sufficient and representative sample.

- The researcher doesn't triangulate the methods of data collection, he uses only questionnaire.

\section{Study population}

The target population of this study consists of selective samples of students from foundation school studies at Caledonian College of Engineering, besides 24 teachers from English Language Department.

The number of samples for this study consists of 90 students who were selected out of all the students at the college, which are approximately 300. Their age ranges from 18 to 23 . All of them had an average of receiving 10 years of formal instruction in English as a foreign language and were about to complete their foundation courses. Most of the subjects have been taught under the same educational system. The number of teachers who responded to the 
questionnaire was 24. Most of the teachers have substantial experience in teaching English language at the tertiary level.

\section{Methodology}

Two versions of questionnaires_were administered to both teachers and students to collect their beliefs and assumptions about CALL. The questionnaires mainly followed a rating scale format. And there are only three open-ended questions asking both students and teachers about their beliefs and suggestions for improving CALL lessons; which skills they would prefer to practise in a CALL lesson besides the technical problems they usually face in CALL lessons.

Moreover, to guarantee reliability, the questionnaires were piloted before administration to iron the wrinkles out and a new version was drafted that was easier with clear instructions for the pupils. The content was reworded and irrelevant questions were taken out to secure the intelligibility of the questionnaire. Questionnaires were administered to 90 randomly selected students from the foundation program. Another version of questionnaire was administered to 24 teachers who teach the programme.

\section{Results}

Presentation and analysis of data collected from students' questionnaire.

1. CALL is useful for me.

As for question (1), 80 students (89\%) considered that CALL lessons are useful to them and 6 students (6\%) reported that they have "no idea", whereas 4 students $(4 \%)$ responded by "disagree". So, the majority of the students (89\%) agreed that CALL is useful to them and they are learning a lot from it.

2. The time allocated for the CALL lesson is enough for me.

In response to question (2), 40 students (44\%) considered the time for the CALL lesson was enough and only 6 students (6\%) reported by "no idea", whereas 54 students $(60 \%)$ said that the time was not sufficient.

\section{CALL lessons are very interesting for me.}

For question (3), 58 students (64\%) reported that CALL lessons were very interesting to them whereas 20 students $(22 \%)$ considered CALL lessons were not interesting to them. So, it is 
proven that the majority of the students consider CALL lessons were interesting to them and they benefited from them.

4. It is better for CALL lesson to be in class rather than the lab.

With regard to this, in question 4 , only 38 students (42\%) reported that it is better for the

CALL lessons to be carried out in the classroom rather than in the laboratory, whereas 20 students (22\%) responded by "no idea" and 43 students (48\%) answered by "disagree". So, it is clear that the majority of the students preferred the lesson to be in the laboratory rather than in the classroom.

5. There are some useful websites where I can learn English.

Concerning this question, 60 students $(67 \%)$ reported that there are some useful websites where they can learn and practise English, whereas 20 students (22\%) responded by "no idea" and 20 students (22\%) reported that there are many websites where they can learn English.

So, the majority of the students $(67 \%)$ are satisfied by using websites to learn English but there are still some of the students who have to be aware of the use of the websites and to know how to use these sites purposefully.

\section{Using a computer is difficult for me.}

As for question (6), 24 students (26\%) considered the use of computer is difficult for them, and 18 students (20\%) responded by saying "no idea", whereas 53 students (58\%) reported that the computer is not difficult for them and they could use it at reasonable ease, without having any difficulty. So, the majority of the students (58\%) are computer literate and they are able to the use the computer efficiently.

\section{I like the way the language is practised in the CALL lesson.}

In response to this question (7), 55 students (63\%) responded by saying "agree"/ "strongly agree" and 27 students (30\%) reported by saying "no idea", whereas only 15 students (17\%) responded "disagree". So, the majority of the students are satisfied by the way language is practiced in the CALL lessons. 
8. Do you always need your teacher's help in CALL lessons?

Concerning this question (8), 41 students (46\%) responded "Yes", whereas 48 students (53\%) reported "No". So, it is proven that most of the students are computer literate and they are capable of using the computer and browse the internet independently.

\section{Presentation of teachers' questionnaire results}

1. CALL classes are useful and motivate my students to learn.

In response to this question (1), 15 teachers (62\%) considered the CALL classes are useful for their students and 3 teachers (13\%) responded "no idea", and only 4 teachers (17\%) reported that the CALL lessons are not useful and not motivating to the students anymore.

2. Students found CALL lessons very interesting.

For this question, 17 teachers $(70 \%)$ reported that students have found CALL lessons very interesting to them and only 5 teachers (13\%) responded "no idea" and no one responded "disagree/ strongly disagree". This means that the great majority of teachers reported that students have found CALL lessons very interesting and enjoyable to them.

3. Students spend enough time on language practice in CALL lesson.

Regarding this question, 6 teachers $(25 \%)$ considered the time allocated for the CALL lesson is enough and only 2 teachers (8\%) responded "no idea", whereas 16 teachers (67\%) considered the time was not enough for the CALL classes.

4. Manythings.org is an interesting site for my students in a CALL lesson.

Concerning this question, 13 teachers (54\%) reported that the website is interesting for students and 7 teachers (29\%) responded "no idea", whereas 4 teachers (17\%) considered it as not useful enough for the students to learn.

5. You like the way CALL lessons are executed.

In response to this question, 9 teachers (38\%) reported that they like the way the lessons are run, whereas 6 teachers $(25 \%)$ responded 'no idea' and only 8 teachers (33\%) reported that they didn't like the way CALL lessons are executed. 
6. Students enjoy the CALL lesson and they are learning a lot from it.

For this question, 14 teachers (58\%) reported that the students enjoy the CALL lessons and they are learning a lot from them, whereas 6 teachers $(25 \%)$ responded "no idea", and 2 teachers $(8 \%)$ reported that the students did not enjoy the CALL lessons anymore.

7. The objectives of CALL lessons are clear for me.

Regarding this question, 12 teachers $(50 \%)$ considered that the objectives of CALL lessons are clear and only 6 teachers $(25 \%)$ responded 'no idea', and 4 teachers $(17 \%)$ considered that the objectives aren't clear to them.

8. CALL program is still young and it is too early to be evaluated.

As the results showed, 11 teachers $(49 \%)$ considered the program was too young to be evaluated whereas 4 teachers (17\%) disagreed with this statement.

\section{Recommendations and implications}

Taking into account the results of the study, the following points are offered as recommendations:

O Computers should be arranged in a better way (user-friendly) to help CALL practitioners to move around easily so as to help students, and to observe them, whether they are in task or off task and to minimize their use of the non-target activities.

O The number of hours should be increased to two hours per week instead of one hour.

- Language labs should be equipped with all necessary equipment. Headphones should be made available for practising listening skills.

○ Teachers should incorporate smart board and black board in their CALL lesson slots.

O Teachers should provide interesting activities that enable students to perform real-life activities and students' awareness of the importance of CALL should be raised.

○ Allow skillful, committed and trained teachers to take charge of CALL lessons.

O The lab technician and teacher should be available during the whole CALL lesson to provide technical help if needed.

○ Independent \& autonomous learning should be encouraged in CALL class and more elearning software and materials should be made available such as Moodle, Hot Potatoes, etc.

O CMS (Computer Monitoring System) and software should be installed. 
- Lesson plans for CALL should be developed for each class and websites should be made available before the class time.

- Tests \& assessments should be carried out online as a part of CALL lessons

- Some CALL materials should be designed and up-loaded into the blackboard so as to be practised in CALL lessons.

This study has contributed some interesting suggestions and answers to improve the CALL program. The great majority of the students and teachers have shown positive attitudes towards the program. Most of the students (if not all) are interested in the program and they are asking for longer time for CALL classes to two hours week. The study puts forward some suggestions and recommendations. These are taken from all the target respondents to improve the CALL program by finding proper teaching strategies, using interactive websites and incorporating both the blackboard and smart board in the CALL lessons.

\section{References}

Al Saidi, M. (2007). Investigating student attitude towards CALL programme in elf-access centre at Sultan Qaboos University: an attempt toward improvement. Retrieved from <http:// www. squ. edu. om/ Portals /28/ Micro\% 20Gallery /forum/ Forum8/ mahmoud. pdf>

Bulut, A. (2005). English Teachers' Barriers to the Use of CALL in University EFL Classes. Retrieved from<http: www.aifbulut.com/eng/projet.html>.

Georgiou, S. L. (2006). The Future of CALL. ELT Journal Volume 6/l4 October 2006. Oxford: Oxford university press.

Beatty, K. (2003). Teaching and Researching Computer Assisted Language Learning. New York: Longman.

Janes, J. (2001) .CALL and the responsibilities of teachers \&administrators. ELT Journal, volume. 5514, October 2001, (pp.360-367).

Lee, K .(2000). English Teachers' Barriers to the Use of Computer-assisted Language Learning. Retrieved from http :<www.itesj.org/articles/lee-callbarriers.html>

Levy, M. (1997). Computer-Assisted Language Learning: context and conceptualization. Oxford: Oxford university press.

McGreal, R. (1988).Computer Assisted Instruction: Non-human but not inhuman. English language Teaching Form, July, 15-17.

Saeed, S. (2006) .CALL an innovative method of language teaching, ELT IN Oman Journal, Volume.1. MoE, (pp.45-47).

Warschauer, M. (2008). Computer Assisted Language Learning: Introduction. Retrieved from http://www.ict4lt.org/en/Warschauer.htm.Wikipedia. Retrieved from htt://Wikipedia.org/wiki/computer-assisted_language_learning. 